\title{
PERFORMANCE EVALUATION OF ARTIFICIAL NEURAL NETWORKS IN ESTIMATING REFERENCE EVAPOTRANSPIRATION WITH MINIMAL METEOROLOGICAL DATA
}

\author{
M.J. DIAMANTOPOULOU ${ }^{1}$ \\ P.E. GEORGIOU ${ }^{2, *}$ \\ D.M. PAPAMICHAIL ${ }^{2}$
}

\author{
${ }^{1}$ Faculty of Forestry and Natural Environment, \\ ${ }^{2}$ Faculty of Agriculture, \\ Aristotle University of Thessaloniki \\ 54124 Thessaloniki, Greece
}

Received: 07/10/10

Accepted: 22/02/11 *to whom all correspondence should be addressed: e-mail: pantaz@agro.auth.gr

\begin{abstract}
Detailed meteorological data required for the equation of FAO-56 Penman-Monteith (P-M) method that was adopted by Food and Agriculture Organization (FAO) as a standard method in estimating reference evapotranspiration $\left(\mathrm{ET}_{\mathrm{o}}\right)$ are not often available, especially in developing countries. The Hargreaves equation (HG) has been successfully used in some locations to estimate $E_{0}$ where sufficient data were not available to use the P-M method. This paper investigates the potential of two Artificial Neural Network (ANN) architectures, the multilayer perceptron architecture, in which a backpropagation algorithm (BPANN) is used, and the cascade correlation architecture (CCANN), in which Kalman's learning rule is embedded in modeling the daily $\mathrm{ET}_{0}$ with minimal meteorological data. An overview of the features of ANNs and traditional methods such as P-M and HG is presented, and the advantages and limitations of each method are discussed. Daily meteorological data from three automatic weather stations located in Greece were used to optimize and test the different models. The exponent value of the HG equation was locally optimized, and an adjusted HGadj equation was used. The comparisons were based on error statistical techniques using $\mathrm{P}-\mathrm{M}$ daily $\mathrm{ET}_{0}$ values as reference. According to the results obtained, it was found that taking into account only the mean, maximum and minimum air temperatures, the selected ANN models markedly improved the daily $\mathrm{ET}_{0}$ estimates and provided unbiased predictions and systematically better accuracy compared with the HGadj equation. The results also show that the CCANN model performed better than the BPANN model at all stations.
\end{abstract}

KEYWORDS: neural network techniques, evapotranspiration, calibration, validation.

\section{INTRODUCTION}

Knowledge of evapotranspiration, which involves the evaporation of water from land surfaces and transpiration by vegetation, is essential for estimating irrigation water requirements (Allen et al., 1998). Methods for estimating evapotranspiration are based on micrometeorological techniques (aerodynamic method, eddy covariance, etc.) or on the use of lysimeters. The methods for estimating evapotranspiration require complex and very costly instruments and are generally recommended only for specific research purposes (Allen et al., 1998). The evapotranspiration rate from a reference crop is called reference evapotranspiration $\left(E T_{0}\right)$ and expresses the evaporating power of the atmosphere at a specific location and time of the year (Allen et al., 1998). The FAO-56 Penman-Monteith (P-M) equation (Allen et al., 1998) was adopted by FAO as a standard method for estimating daily $\mathrm{ET}_{0}$, as it provides more consistent $\mathrm{ET}_{0}$ estimates and has been shown to perform better than other $\mathrm{ET}_{0}$ methods. However, the detailed meteorological data required by the P-M equation are not often available, especially in developing countries. Under such conditions, simplified or empirical equations, which require less meteorological data, should be used.

Allen et al. (1998) have proposed that when sufficient or reliable data to apply the P-M equation are not available, then the Hargreaves equation (HG) can be used. The HG equation (Hargreaves et al., 1985) requires only extraterrestrial radiation and daily mean, maximum and minimum air 
temperature, which are usually available at most weather stations worldwide (Droogers and Allen, 2002). Extraterrestrial radiation can be calculated for a certain day and location by using the estimated daylight hours according to certain formulas (Allen et al., 1998). Consequently, only minimum and maximum temperatures are the parameters that require observation. This method works best for weekly or longer predictions, although some accurate $\mathrm{ET}_{0}$ daily estimations have been reported in the literature (Hargreaves and Allen, 2003; Vanderlinden et al., 2004). Several studies have attempted to improve the accuracy of the Hargreaves equation (Samani, 2000; Droogers and Allen, 2002; Vanderliden et al., 2004; Trajkovic, 2007). Droogers and Allen (2002) fitting the two parameters of $H G$ equation using the $P-M$ derived $E T_{0}$ values did not improve estimates by the HG method substantially. Samani (2000) proposed a relationship between one coefficient and the daily temperature range, but Vanderlinden et al. (2004) found that adjusting the estimates with the Samani method does not produce more accurate results. They proposed a new relationship between the adjusted Hargreaves coefficient and the rate of the average temperature to the average daily temperature range in the region of Andalusia (S. Spain) for the regional adjustment of the Hargreaves coefficient. Trajkovic (2007) presented an adjusted Hargreaves equation with the exponent value locally optimized for the Western Balkans area. The HG equation adjusted above gave more accurate results. In this paper, the exponent value of the HG equation was locally optimized and the adjusted (HGadj) equation was used.

In recent years, Artificial Neural Network (ANN) models have become extremely popular for prediction and forecasting in a number of areas, including finance, power generation, medicine, water resources and environmental science (Benvenuto and Marani, 2000; Maier and Dandy, 2000; Loukas et al., 2002; Lekkas et al., 2004; Wang et al., 2009). The ANN models are quite appropriate for the simulation of nonlinear processes, which is the case for the evapotranspiration process. Several researchers have used ANN models to estimate or forecast evapotranspiration as a function of climatic data (Kumar et al., 2002; 2008; 2009; Sudheer et al., 2003; Trajkovic et al., 2003; Trajkovic, 2005; 2007; Keskin and Terzi, 2006; Khoob, 2008; Kim and Kim, 2008; Kisi, 2006; 2007; 2008; Landeras et al., 2009). It is important to note that in most of the above papers, the ANNs are considered as back-propagation artificial neural networks (BPANN). Theoretically, feed-forward neural networks can approximate any nonlinear function, and thus the backpropagation algorithms are popular for training feed-forward neural networks. However, the BPANN models have disadvantages, such as (a) a dependence on the choice of the initial weights and number of hidden neurons, (b) very slow convergence rapids, (c) a sensitivity to noise in the training data sets and (d) a poor generalization for complicated nonlinear functions. In this paper, in order to evaluate the potential of BPANN models to estimate the daily $\mathrm{ET}_{0}$ with minimal meteorological data and in an effort to test an alternative procedure in the hopes of overcoming some of the disadvantages of the BPANN models, a Cascade Correlation Artificial Neural Network (CCANN) model in which Kalman's learning rule is embedded was developed. To the knowledge of the authors, no work has been reported in the literature that has applied the CCANN model to ET。 estimation.

The objective of this study was to test BPANN and CCANN models for estimating daily $\mathrm{ET}_{\circ}$ with minimum meteorological data as a function of the mean, maximum and minimum air temperatures and extraterrestrial radiation and finally to compare the adjusted HGadj equation with the ANN models. The comparisons were based on error statistical techniques using $\mathrm{P}-\mathrm{M}$ daily $\mathrm{ET}_{\mathrm{o}}$ values as a reference.

\section{MATERIALS AND METHODS}

\section{Study area and meteorological data sets}

The data used for training and validating the ANNs were obtained from daily meteorological data measured in an Automatic Weather Station (AWS) located at Piperia station in Northern Greece. Additionally, this study also evaluated the adoption of the developed BPANN and CCANN models with minimal meteorological data at Piperia station as models for estimating daily $\mathrm{ET}_{\mathrm{o}}$ in two other AWSs located at Gomati and at Larisa, in Greece. The three AWSs are located in agricultural areas (Figure 1). The meteorological data measured and used in this study are: mean daily air temperature ( $\left.T_{\text {mean }}\right)$; maximum and minimum air temperature $\left(T_{\max }\right.$ and $\left.T_{\min }\right)$; mean daily relative humidity $(R H)$; mean daily wind speed $(u)$; and daily net radiation $\left(R_{n}\right)$. 


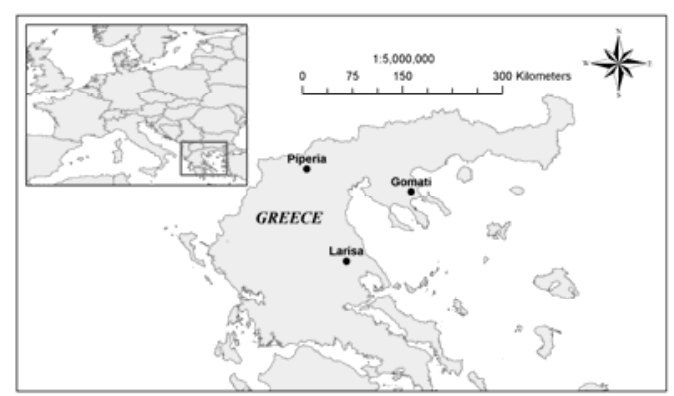

Figure 1. Map of meteorological stations

\section{The FAO-56 Penman-Monteith and Hargreaves methods}

In this study, the performance of the HGadj, BPANN and CCANN models was compared to the conventional FAO-56 Penman-Monteith (P-M) method. This method is the standard procedure when there is no measured lysimeter data (Allen et al., 1998; Alexandris et al., 2006; Georgiou and Papamichail, 2008). Although in practice the best way to test the performance of the abovementioned methods would be to compare their performances against the lysimeter-measured data, this data set is not available for the study area. According to Allen et al. (1998), the P-M method is summarized by the following equation:

$$
\mathrm{ET}_{\mathrm{P}-\mathrm{M}}=\left[0.408 \Delta\left(\mathrm{R}_{\mathrm{n}}-\mathrm{G}\right)+\mathrm{Y} \frac{900}{\mathrm{~T}+273} \mathrm{u}_{2}\left(\mathrm{e}_{\mathrm{s}}-\mathrm{e}_{\mathrm{a}}\right)\right] /\left[\Delta+\mathrm{v}\left(1+0.34 \mathrm{u}_{2}\right)\right]
$$

where $E T_{P-M}$ is the reference evapotranspiration $\left(\mathrm{mm} \mathrm{d}^{-1}\right), R_{n}$ is the daily net radiation (MJ m $\mathrm{m}^{-2} \mathrm{~d}^{-1}$ ), $\mathrm{G}$ is the soil heat flux (MJ m$\left.{ }^{-2} \mathrm{~d}^{-1}\right)$, $T$ is the average daily air temperature at a height of $2 \mathrm{~m}\left({ }^{\circ} \mathrm{C}\right), \mathrm{u}_{2}$ is the daily mean of the wind speed at a height of $2 \mathrm{~m}\left(\mathrm{~m} \mathrm{~s}^{-1}\right), e_{\mathrm{s}}$ is the saturation vapor pressure $(\mathrm{kPa}), \mathrm{e}_{\mathrm{a}}$ is the actual vapor pressure $(\mathrm{kPa}), \Delta$ is the slope of the saturation vapor pressure versus the air temperature curve $\left(\mathrm{kPa}^{\circ} \mathrm{C}^{-1}\right)$, and $\mathrm{y}$ is the psychrometric constant $\left(\mathrm{kPa}{ }^{\circ} \mathrm{C}^{-1}\right)$. All parameters were calculated using equations provided by Allen et al. (1998). The soil heat flux (G) was assumed to be zero over the calculation time step period (24 hours) (Allen et al., 2005).

The Hargreaves equation (Hargreaves and Samani, 1985; Hargreaves and Allen, 2003) can be written as:

$$
\mathrm{ET}_{\mathrm{HG}}=0.0023 \mathrm{R}_{\mathrm{a}}\left(\mathrm{T}_{\text {mean }}+17.8\right)\left(\mathrm{T}_{\text {max }}-\mathrm{T}_{\text {min }}\right)^{\mathrm{b}}
$$

where $E T_{H G}$ is the computed reference evapotranspiration by the HG method $\left(\mathrm{mm} \mathrm{d}^{-1}\right)$, $\mathrm{R}_{\mathrm{a}}$ is the water equivalent of the extraterrestrial radiation $\left(\mathrm{mm} \mathrm{d}^{-1}\right)$ computed according to Allen et al. (1998), $\mathrm{T}_{\max }$ and $\mathrm{T}_{\min }$ are the daily maximum and minimum air temperature $\left({ }^{\circ} \mathrm{C}\right), \mathrm{T}_{\text {mean }}$ is the daily mean air temperature $\left({ }^{\circ} \mathrm{C}\right)$ computed as the average of $T_{\max }$ and $T_{\min }$ and $b$ is an empirical coefficient set to 0.5 by definition. In this study, the b coefficient of the HG model (Eq. 2) was estimated by regression analysis across the calibration data set (1994-1998) at Piperia station, and the performance of the locally optimized HG model was evaluated by the validation data set (2005) at the three stations. Finally, the locally adjusted ( $E T_{H G a d j}$ ) equation with b equal to 0.39899 was used instead of the HG equation with $b$ equal to 0.5 . The locally adjusted ( $\left.E T_{\text {HGadj }}\right)$ equation can be written as:

$$
E T_{\text {HGadj }}=0.0023 R_{a}\left(T_{\text {mean }}+17.8\right)\left(T_{\text {max }}-T_{\text {min }}\right)^{0.39899}
$$

\section{Artificial neural networks methodology}

Back-propagation is the most popular algorithm for training ANNs. It is essentially a gradient descent technique that minimizes the network error function. The back-propagation artificial neural network models (BPANN) have already been described and are used widely (Fausett, 1994; Haykin, 1994). In this paper, standard back-propagation learning was used. This algorithm makes use of two parameters that control the rate at which learning takes place. The first is a momentum term, which is generally used to accelerate the convergence and to avoid local minima. The second is the learning rate. The effectiveness and convergence of training depends significantly on the value of the learning rate. If it is too high, then the search may miss a valley on the error surface. In contrast, if it is too small, the convergence will be very slow. The number of neurons in the hidden layer of the neural network is finalized after a trial and error procedure using different combinations of learning 
rates and momentum factors. Each combination of a learning rate and momentum factor is tested for different numbers of hidden neurons.

Fahlman and Lebiere (1990) proposed the Cascade Correlation algorithm to deal with several perceived problems with the popular back-propagation algorithm. The Cascade Correlation has several advantages over existing algorithms; it learns very quickly, the network determines its own size and topology, and it requires no back-propagation of error signals through the connections of the network. It has also been shown to perform well experimentally (Drago and Ridella, 1994; Prechelt, 1997). The Cascade Correlation Artificial Neural Network (CCANN) is a feed-forward type of network, which is a supervised algorithm for multilayer feed-forward ANNs. The cascade correlation algorithm starts the training without any hidden nodes and trains the network, iteratively repeating the process for an increasing number of nodes until no further improvement in network performance can be obtained. Because of its dynamic expansion that continues until the problem is successfully learned, the cascade correlation algorithm automatically creates a suitable network architecture for a given problem (Karunanithi et al., 1994). By using cascade correlation, the neural network designer is relieved of the task of having to guess at the configuration of the architecture for a particular problem. Furthermore, studies have shown cascade correlation to be a faster algorithm and to be better able to converge (Fahlman and Lebiere, 1990; Drago and Ridella, 1994).

Kalman's learning algorithm (Demuth and Beale, 2001; Grewal and Andrews, 2001) was used. The Kalman learning rule seems to be a key feature of the ANN. This learning rule is acceptable for forecasting the type of problems where the number of inputs is not too large (Grewal and Andrews, 2001). A Kalman filter (Brown and Hwang, 1992; Rivals and Personnaz, 1998; Demuth and Beale, 2001; Grewal and Andrews, 2001; Li et al., 2002) attempts to estimate the state of a system that can be modeled as a linear system driven by additive white Gaussian noise and where the available measurements are linear combinations of the system states that are corrupted by additive white Gaussian noise (Li et al., 2002). A detailed description of the Cascade Correlation architecture where Kalman's learning rule is embedded can be found in Diamantopoulou (2010). The first important parameter that controls the Kalman learning rule is the hidden noise factor (HNF). The square of its value is used to initialize the measurement noise covariance matrix for training hidden candidate weights. This factor has a significant effect on the ability of the network to generalize, as it tends to inhibit the large weights and complexity of the model. The second parameter is the value of the maximum variance (MV). This value is used to initialize the diagonal value of the error covariance matrix for the Kalman estimates of the weights. Additionally, the work of Rivals and Personnaz (1998) analyzes the cases of the different initial values for the Kalman Filter training algorithm and provides advice on how to choose the initial values of the system error covariance and process noise error in the Kalman recursion.

The choice of the activation function was also investigated. The activation or transfer function for neurons in the hidden layer used in this paper is the hyperbolic tangent function (Fausett, 1994).

\section{Performance evaluation}

A model's performance was evaluated using a variety of standard statistical indexes including the correlation coefficient (R), the mean absolute error (MAE) and the root mean square error (RMSE). A high R, a low MAE and a low RMSE imply good model performance and vice versa.

In addition, a model's performance was evaluated using the following criteria: The relative error (RE) (Diamantopoulou et al., 2009) is a proportional measure of the error and provides information about the predictive capability of the model. A low RE implies good model performance and vice versa.

The signal-to-noise ratio (SNR) (Diamantopoulou et al., 2009) involves the standard error of the estimated and the standard deviation of the observed values of the output variable. A low SNR implies good model performance and vice versa.

The performance index (C) (Willmott, 1981) was used to quantify the adjustment level between observed and estimated values. A high $\mathrm{C}$ implies good model performance and vice versa.

Furthermore, to evaluate the models and to make unbiased estimations, the bias $\%$ as the mean percentage estimation errors derived by the ANN models and HGadj method for all data sets and all stations, the nonparametric tolerance intervals and the mean square bias of the percentage errors (Msb\%), were calculated. Taking into account the fact that if the errors in absolute terms are normally distributed, then the percent errors may not be (Reynolds, 1984), the $5 \%$ trimmed mean 
and the jackknife sample standard deviation of the error were used as more robust location estimators (Hoaglin et al., 1985).

In order to provide limits to contain a specified proportion of the percentage estimation error distribution over the long term, the nonparametric tolerance intervals were calculated as follows: Bias $\% \pm$ nonparametric tolerance length. The tolerance intervals provide the range that will contain $95 \%$ of the distribution of the percentage estimation errors with $95 \%$ confidence.

\section{RESULTS AND DISCUSSION}

\section{Estimating daily $\mathrm{ET}_{\mathrm{o}}$ by the P-M and HGadj methods}

The P-M and HGadj methods were used to estimate daily $E T_{0}\left(\mathrm{~mm} \mathrm{~d}^{-1}\right)$ at Piperia station in years 1994-1998 and in year 2005 and at Gomati and Larisa stations in year 2005. The related information from three weather stations and the average daily values of the meteorological parameters $\left(T_{\max }\right.$, $\mathrm{T}_{\text {min }}, \mathrm{T}_{\text {mean }}$ ) and the averaged daily sum value of $E T_{0}$ computed by P-M equation are given in Table 1.

Table 1. Average station daily values for meteorological parameters $\left(E T_{0}(P-M)\right.$ is the averaged daily sum value computed by $\mathrm{P}-\mathrm{M}$ equation)

\begin{tabular}{llcccc}
\hline Station (Lat., Long., Alt.) & Period & $\begin{array}{c}\mathrm{T}_{\max } \\
\left({ }^{\circ} \mathrm{C}\right)\end{array}$ & $\begin{array}{c}\mathrm{T}_{\min } \\
\left({ }^{\circ} \mathrm{C}\right)\end{array}$ & $\begin{array}{c}\mathrm{T}_{\operatorname{mean}} \\
\left({ }^{\circ} \mathrm{C}\right)\end{array}$ & $\begin{array}{c}\mathrm{ET}_{\mathrm{o}}(\mathrm{P}-\mathrm{M}) \\
\left(\mathrm{mm} \mathrm{d}^{-1}\right)\end{array}$ \\
\hline Piperia $\left(40^{\circ} 58^{\prime}, 22^{\circ} 02^{\prime}, 160 \mathrm{~m}\right)$ & $(1994-98)^{\star}$ & 20.87 & 7.78 & 14.33 & 2.55 \\
Piperia $\left(40^{\circ} 58^{\prime}, 22^{\circ} 02^{\prime}, 160 \mathrm{~m}\right)$ & $(2005)^{\star *}$ & 21.27 & 7.56 & 14.42 & 2.62 \\
Gomati $\left(40^{\circ} 24^{\prime}, 23^{\circ} 43^{\prime}, 100 \mathrm{~m}\right)$ & $(2005)^{\star *}$ & 19.61 & 9.78 & 14.70 & 2.66 \\
Larisa $\left(39^{\circ} 39^{\prime}, 22^{\circ} 25^{\prime}, 73.6 \mathrm{~m}\right)$ & $(2005)^{\star *}$ & 21.58 & 8.79 & 15.19 & 2.52 \\
\hline
\end{tabular}

${ }^{*}$ Calibration period, ${ }^{* *}$ Validation period

The agreement between $\mathrm{ET}_{0}(\mathrm{HGadj})$ and $\mathrm{ET}_{0}(\mathrm{P}-\mathrm{M})$ was good (Table 2). The high values of the correlation coefficients $(R>0.91)$ at all stations reveal a reliable performance of the HGadj method, but the HGadj method at the Piperia and Gomati stations was underestimated when ETo was high. Considering all stations, for the validation year, the values of R, MAE, RMSE, RE, SRN and C statistics for the HGadj method (Table 2) ranged from 0.920 to $0.958,0.415 \mathrm{~mm} \mathrm{~d}^{-1}$ to $0.526 \mathrm{~mm} \mathrm{~d}^{-1}$, $0.553 \mathrm{~mm} \mathrm{~d}^{-1}$ to $0.691 \mathrm{~mm} \mathrm{~d}^{-1}, 0.208$ to $0.299,0.435$ to 0.511 , and 0.870 to 0.903 , respectively. The MAE yields a more balanced perspective of the goodness-of-fit at moderate $E_{0}$ values, whereas the RMSE measures the goodness-of-fit relevant to high $\mathrm{ET}_{0}$ values. The above results indicate that the statistics of the HGadj method validation performance were sufficient.

Table 2. Statistics of HGadj method performance at all stations

\begin{tabular}{lcccccccc}
\hline Station & Period & $\begin{array}{c}\text { Patte- } \\
\text { rns }\end{array}$ & $\mathrm{R}$ & $\begin{array}{c}\mathrm{MAE} \\
\left(\mathrm{mm} \mathrm{d}^{-1}\right)\end{array}$ & $\begin{array}{c}\mathrm{RMSE} \\
\left(\mathrm{mm} \mathrm{d}^{-1}\right)\end{array}$ & $\mathrm{RE}$ & SNR & $\mathrm{C}$ \\
\hline Piperia & $1994-98$ & 1826 & 0.914 & 0.461 & 0.725 & 0.284 & 0.405 & 0.872 \\
Piperia & 2005 & 365 & 0.920 & 0.478 & 0.691 & 0.266 & 0.500 & 0.870 \\
Gomati & 2005 & 365 & 0.958 & 0.526 & 0.690 & 0.299 & 0.511 & 0.883 \\
Larisa & 2005 & 365 & 0.947 & 0.415 & 0.553 & 0.208 & 0.435 & 0.903 \\
\hline
\end{tabular}

\section{Estimating daily $\mathrm{ET}_{0}$ by the ANN models}

In this paper, BPANN and CCANN models were developed for estimating the daily $\mathrm{ET}_{0}$ at Piperia station by using as inputs the meteorological data which were used by the HGadj method. These inputs include the daily mean, maximum and minimum air temperature $\left({ }^{\circ} \mathrm{C}\right)$ and the daily extraterrestrial radiation $\left(\mathrm{MJ} \mathrm{m} \mathrm{m}^{-2} \mathrm{~d}^{-1}\right)$. The last variable was calculated as a function of the local latitude and Julian day, according to the equations presented by Allen et al. (1998). Thus, the proposed models require only daily values of air temperatures to estimate the $\mathrm{ET}_{0}$. The single output is the daily $\mathrm{ET}_{\mathrm{o}}$ estimated by the P-M method with all meteorological data required by this method. In order to evaluate the relative importance of the four variables used as inputs for the construction of the BPANN and CCANN models, a sensitivity analysis was conducted for both architectures. In the sensitivity analysis, the calibration data set (1994-98) at Piperia station was submitted to the network repeatedly, with each variable in turn treated as missing, and the resulting network error was recorded. Finally, the ratio between the error with an omission of each variable and the error obtained using all variables was calculated, and it was found to be much higher than one, for all variables, meaning that every variable contributes significantly to the estimation of the output values. 
The ANN models were developed by using the daily data from 1994-1998 at Piperia station as a calibration period and from 2005 at the three stations as a validation period (Figure 1, Table 1).

To avoid overfitting in ANN model building, the $\mathrm{K}=10$ fold cross-validation resampling technique was used. The advantage of this method is that all of the examples in the calibration data set are eventually used for both training and testing. Following this method, the calibration data set was randomly partitioned into training (the $90 \%$ of the calibration data) and testing (the remaining $10 \%$ of the calibration data) data sets. After the selection of the architecture and the training parameters, the model was trained using the training data set. The model was evaluated using the test data set. The above procedure was repeated for each $\mathrm{K}=10$ experiments, using $\mathrm{K}-1=9$ folds for training and the remaining one for testing. The entire procedure was repeated many times using different training parameters. Finally, training was stopped when the generalization ability reached a maximum. This ability was measured by the average error rate of the cross-validation examples.

The multilayer perceptron architecture using the back-propagation algorithm was used to train the BPANN models. The back-propagation learning rate and the momentum factor are two parameters that must be defined for back-propagation training. The learning rate and momentum factor values were finalized after examining different combinations. Each combination of learning rate and momentum factor was examined for different numbers of hidden neurons. The best values for the learning rate and the momentum factor were 0.1 and 0.3 , respectively. The number of nodes in the hidden layer of the neural network that was used for various training models were $1,2,3, \ldots 11$. The network has been trained for 2000 epochs, as there was very negligible reduction of the mean square error (MSE) and the RMSE values after 2000 epochs. Nine hidden nodes were chosen in the hidden layer for the trained model because the lowest residual error (RMSE) for the training set was obtained.

Different CCANN models were tested to determine the optimum number of hidden layers and the number of nodes in each. The architecture of the best CCANN model for forecasting the daily $\mathrm{ET}_{\mathrm{o}}$ at Piperia station is composed of one input layer with four input variables, which are the daily mean, maximum and minimum air temperature $\left({ }^{\circ} \mathrm{C}\right)$ and the daily extraterrestrial radiation $\left(\mathrm{MJ} \mathrm{m}^{-2} \mathrm{~d}^{-1}\right)$, one hidden layer with eight nodes and one output layer with one output variable. The number of nodes in this one hidden layer was determined based on the maximum value of the correlation coefficient. The output $\mathrm{ET}_{0}$ represents the daily $\mathrm{ET}_{0}$ estimated by the P-M method.

The values of the hidden noise factor and the maximum variance for the Kalman learning rule were decided after examining different combinations. The hidden noise factor was used as a regularization term. The effect of a high hidden noise factor value is to reduce the dependence of learning from individual records. General trends in the data are reinforced. Hidden noise factor HNF $=1.0$ (this value is set for clean data), 2.0, 5.0, 10.0, 20.0, 30.0, 40.0 and 50.0 (this value is set for very noisy data) and the maximum variance $M V=500,1000,2000,3000,4000$ and 5000, were considered to find the best combinations. For the training of the CCANN models the best combination of the hidden noise factor value and the maximum variance value was equal to 5.0 and 2000 , respectively.

After the training process, the adoption of the developed BPANN and CCANN models with minimum meteorological data at Piperia station for the year 2005 and in two other weather stations, which are located at Gomati and Larisa (Figure 1), was also investigated. The best BPANN and CCANN models and the statistics of their performances for all data sets including the correlation coefficient $(R)$, the mean absolute error (MAE), the root mean square error (RMSE), the relative error (RE), the signal-to-noise ratio (SNR) and the performance index (C), are given in Table 3 . The notation (ETo/CCANN: 4-8-1) (Table 3) means that the best architecture of the specific CCANN model is composed of one input layer with four input variables, one hidden layer with eight nodes and one output layer with one output variable. Corresponding notation is given for the selected BPANN model (Table 3).

For all stations (Table 3), the values of R, MAE, RMSE, RE, SRN and C statistics for the BPANN model validation performance ranged from 0.939 to $0.956,0.398 \mathrm{~mm} \mathrm{~d}^{-1}$ to $0.444 \mathrm{~mm} \mathrm{~d}^{-1}, 0.549 \mathrm{~mm}$ $\mathrm{d}^{-1}$ to $0.609 \mathrm{~mm} \mathrm{~d}^{-1}, 0.202$ to $0.238,0.356$ to 0.375 , and 0.914 to 0.929 , respectively. In addition, for all stations (Table 3), the values of R, MAE, RMSE, RE, SRN and C statistics for the CCANN model validation performance ranged from 0.949 to $0.957,0.411 \mathrm{~mm} \mathrm{~d}^{-1}$ to $0.437 \mathrm{~mm} \mathrm{~d}^{-1}, 0.545 \mathrm{~mm} \mathrm{~d}^{-1}$ to $0.581 \mathrm{~mm} \mathrm{~d}^{-1}, 0.203$ to $0.231,0.349$ to 0.351 , and 0.923 to 0.933 , respectively. 
Table 3. Statistics of the BPANN and CCANN models performance, at all stations

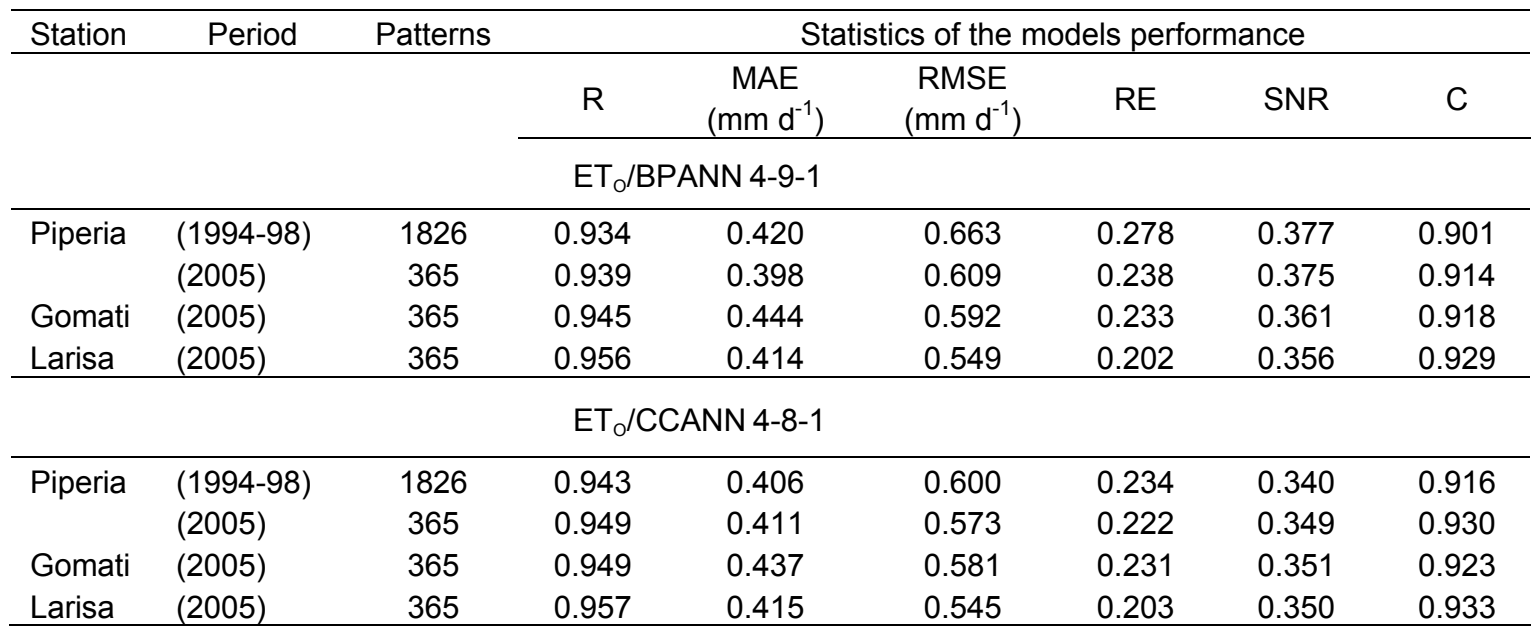

(a)

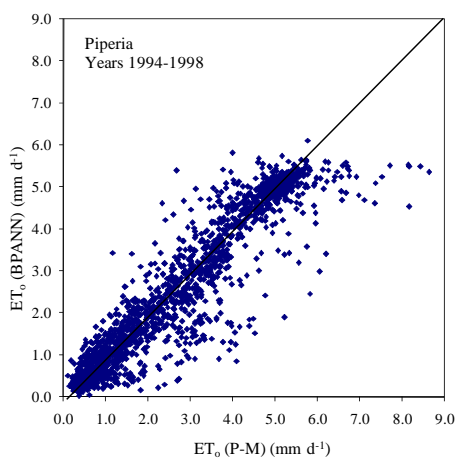

(d)

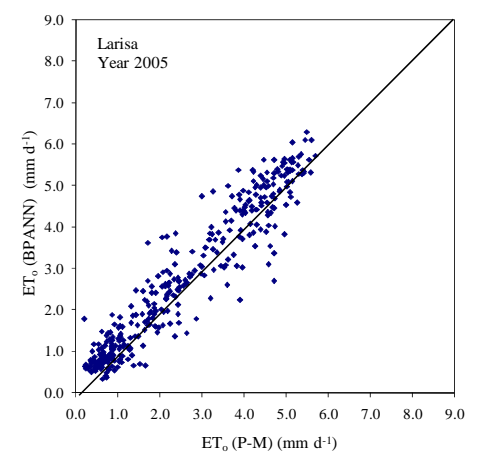

(g)

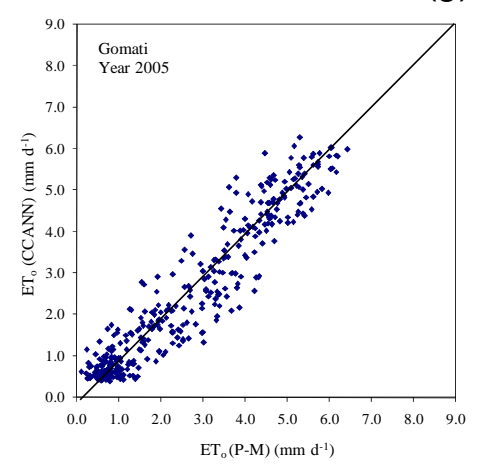

(b)

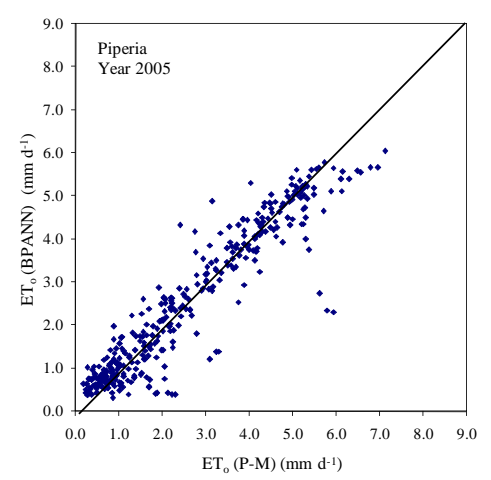

(e)

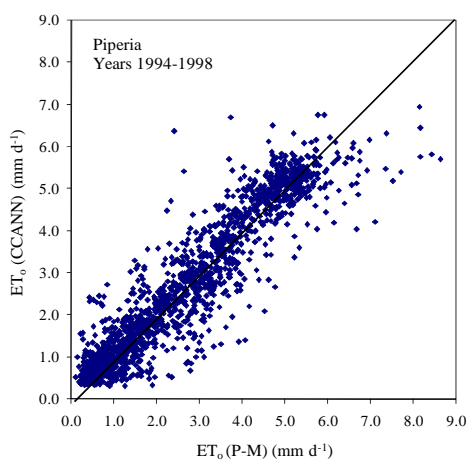

(h)

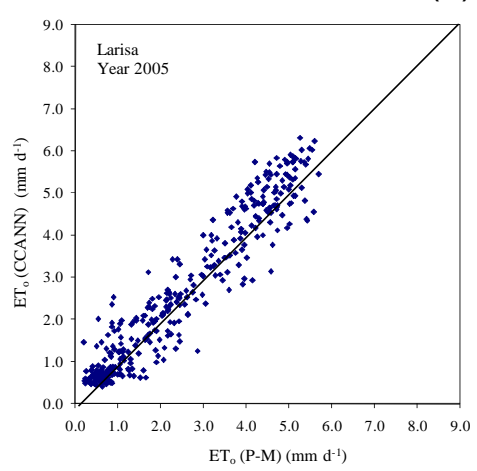

(c)

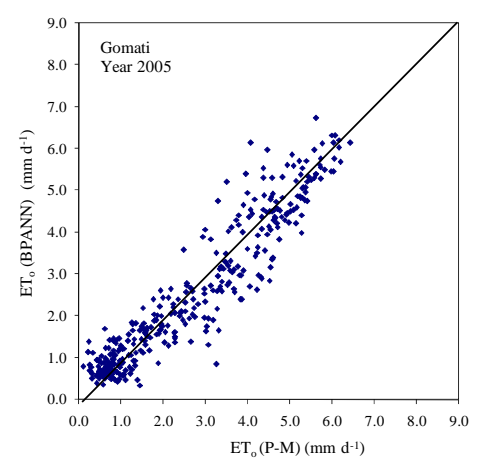

(f)

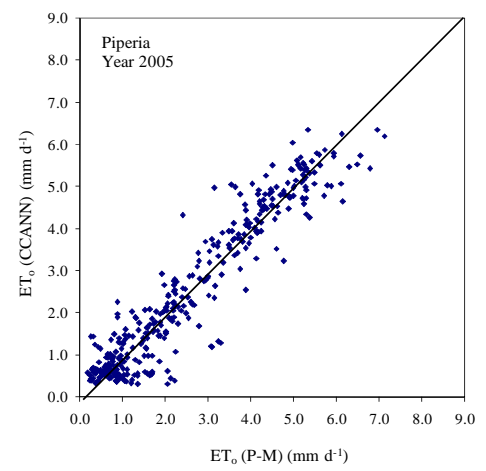

$\mathrm{ET}_{0}(\mathrm{P}-\mathrm{M})\left(\mathrm{mm} \mathrm{d}^{-1}\right)$

Figure 2. Daily $\mathrm{ET}_{\mathrm{o}}$ values estimated by the BPANN model (a,b,c,d) and the CCANN model (e,f,g,h) versus the corresponding daily $\mathrm{ET}_{\mathrm{o}}$ values computed by the P-M method, at all stations 
From the above results (Table 3), we can consider that the statistical values of the CCANN model validation performance, which used data from all stations, were better than those of the BPANN model validation performance. The values of the correlation coefficient $(R)$ and the performance index $(C)$ were very high; the highest for all data sets for the CCANN model (Table 3 ) meaning that the $\mathrm{ET}_{0}$ values estimated by the CCANN model were closely related to those computed by the P-M method. In addition, according to the predictive ability of the models (Table 3 ), the error values (RMSE and RE) and the signal-to-noise ratio values (SRN) suggested that the CCANN model was superior to the BPANN model for all different data sets. Because the validation data sets at Gomati and Larisa stations were not used by the selected BPANN and CCANN models, the accurate predictions of these data sets (Table 3 ) demonstrated the adequacy and the potential of both selected models for estimating the daily $\mathrm{ET}_{\mathrm{o}}$ at stations that are located beyond the station in which the calibration data were measured. Furthermore, according to the statistical values of the BPANN model (Table 3) and the HGadj method (Table 2), the statistical values of the BPANN model are better than those of the HGadj method.

The daily $\mathrm{ET}_{0}$ values estimated by the P-M method at Piperia station for the calibration years and the validation year and at Gomati and Larisa stations for the validation year were compared with the corresponding values estimated by the selected BPANN and CCANN models (Table 3). The comparisons are shown in Figure 2.

Figure 2 shows that the daily $\mathrm{ET}_{0}$ values estimated by both the BPANN and CCANN models during the calibration and validation years at all stations match well and the effectiveness of these models is clear, with the daily $\mathrm{ET}_{\mathrm{o}}$ values estimated by the CCANN model being better than those by the BPANN model.

To evaluate of the models and make unbiased estimations, the bias (\%) as the mean percentage of estimation errors derived by all different estimating models was calculated and is provided in Table 4. Both normal probability plots and a Lilliefors statistical test (Norusis, 2000) tested the normality of the percentage errors of all estimation methods. This exploration showed a significant departure from normality $(a=0.05)$ for all cases. For this reason, the $5 \%$ standard deviation of the errors of the trimmed mean and the jackknife sample as more robust location estimators (Hoaglin et al. 1985), were used to estimate tolerance interval limits (Table 4).

Table 4. Bias (\%), nonparametric tolerance interval limits and mean square bias of the percentage errors (Msb\%) of the daily $\mathrm{ET}_{0}$ values estimated by the HGadj method and the BPANN and CCANN models, at all stations

\begin{tabular}{|c|c|c|c|c|c|c|}
\hline \multirow[t]{2}{*}{ Station } & \multirow[t]{2}{*}{ Period } & \multirow[t]{2}{*}{ Model } & \multirow[t]{2}{*}{${ }^{1}$ Bias (\%) } & \multicolumn{2}{|c|}{$\begin{array}{c}\text { Nonparametric tolerance } \\
\text { interval }\end{array}$} & \multirow[t]{2}{*}{ Msb (\%) } \\
\hline & & & & Lower limit & Upper limit & \\
\hline \multirow{3}{*}{ Piperia } & \multirow{3}{*}{ 1994-98 } & HGadj & $-10.694^{*}$ & -63.84 & 42.45 & 756.12 \\
\hline & & BPANN & $6.692^{*}$ & -33.94 & 47.32 & 474.44 \\
\hline & & CCANN & $-5.510^{*}$ & -49.24 & 63.84 & 464.74 \\
\hline \multirow{3}{*}{ Piperia } & \multirow{3}{*}{2005} & HGadj & $-8.159^{*}$ & -64.66 & 48.34 & 791.90 \\
\hline & & BPANN & $-3.758^{*}$ & -55.12 & 47.60 & 613.47 \\
\hline & & CCANN & $-0.339^{*}$ & -50.25 & 49.57 & 566.09 \\
\hline \multirow{3}{*}{ Gomati } & \multirow{3}{*}{2005} & HGadj & $3.986^{*}$ & -47.69 & 55.66 & 622.49 \\
\hline & & BPANN & $-0.074^{*}$ & -50.21 & 50.06 & 571.07 \\
\hline & & CCANN & $3.314^{*}$ & -43.14 & 49.77 & 501.37 \\
\hline \multirow{3}{*}{ Larisa } & \multirow{3}{*}{2005} & HGadj & $-13.654^{*}$ & -67.99 & 40.69 & 857.31 \\
\hline & & BPANN & $-14.42^{*}$ & -66.66 & 37.81 & 827.90 \\
\hline & & CCANN & $-9.074^{*}$ & -58.77 & 40.63 & 643.53 \\
\hline
\end{tabular}

${ }^{1}$ Bias (\%): (+) indicates an underestimation, (-) indicates an overestimation

* Indicates bias not significantly different from zero $(a=0.05)$

Table 4 shows that all different estimating models gave unbiased results. The values of the mean square bias of the percentage errors (Msb\%) of the CCANN model were significantly lower than those of the BPANN model and the HGadj method for all data sets and all stations.

From Figure 2 and Tables 2, 3 and 4 it is clear that the selected CCANN model of the Cascade Correlation algorithm in which Kalman's learning rule is embedded was superior to the BPANN model and the HGadj method and leads to higher estimation accuracy for all data sets and all stations. 


\section{CONCLUSIONS}

The CCANN model was found to perform better than the BPANN model and the HGadj method, even in the case of the two stations that are located beyond the station in which the calibration data were measured. The good results of the CCANN model are of significant practical use because the temperature-based CCANN model can be used when relative humidity, radiation and wind speed data are not available. The developed CCANN model of a Cascade Correlation algorithm in which Kalman's learning rule is embedded has the ability to estimate the daily $\mathrm{ET}_{0}$ with reasonable accuracy and to give a generalized solution.

\section{REFERENCES}

Allen R.G., Pereira L.S., Raes D. and Smith M. (1998), Crop evapotranspiration. Guidelines for computing crop water requirements, FAO Irrigation and Drainage Paper 56, FAO, Rome.

Allen R.G., Walter I.A., Elliott R.L., Howell T.A., Itenfisu D., Jensen M.E. and Snyder R.L. (2005), The ASCE standardized reference evapotranspiration equation, Task Committee on Standardization of Reference Evapotranspiration of the EWRI of the ASCE, USA.

Alexandris S., Kerkides P. and Liakatas A. (2006), Daily reference evapotranspiration estimates by the "Copais" approach, Agricultural Water Management, 82, 371-386.

Benvenuto F. and Marani A. (2000), Neural networks for environmental problems: Data quality control and air pollution nowcasting, Global NEST Journal, 2, 281-292.

Brown R.G. and Hwang P.Y.C. (1992), Introduction to random signals and applied Kalman filtering, $2^{\text {nd }}$ ed., Wiley, New York.

Demuth H. and Beale M. (2001), Neural network toolbox, For use with Matlab ${ }^{\circledR}$, User's Guide, V4.

Diamantopoulou M.J. (2010), Filling gaps in diameter measurements on standing tree boles in the urban forest of Thessaloniki, Greece, Environmental Modelling and Software, 25, 1857-1865.

Diamantopoulou M.J., Milios E., Doganos, D. and Bistinas I. (2009), Artificial neural network modeling for reforestation design through the dominant trees bole-volume estimation, Natural Resource Modelling, 22, 511-543.

Drago G.P. and Ridella S. (1994), Convergence properties of cascade correlation in Function Approximation, Neural Computing and Applications, 2, 142-147.

Droogers P. and Allen R.G. (2002), Estimating reference evapotranspiration under inaccurate data conditions, Irrigation and Drainage Systems, 16, 33-45.

Fahlman S.E. and Lebiere C. (1990), The cascade correlation learning architecture. p. 524-532, In: Touretsky, D.S., ed. Advances in Neural Information Processing Systems 2, San Mateo, CA, Morgan Kaufmann.

Fausett L. (1994), Fundamentals of neural networks architectures, Algorithms and applications, Prentice Hall, USA.

Georgiou P.E. and Papamichail D.M. (2008), Optimization model of an irrigation reservoir for water allocation and crop planning under various weather conditions, Irrigation Science, 26, 487-504.

Grewal M.S. and Andrews A.P. (2001), Kalman filtering, Theory and practice using MATLAB ${ }^{\circledR}, 2^{\text {nd }}$ ed. Wiley, New York.

Hargreaves G.H. and Allen R.G. (2003), History and evaluation of Hargreaves evapotranspiration equation, Journal of Irrigation and Drainage Engineering, 129, 53-63.

Hargreaves G.H. and Samani Z.A. (1985), Reference crop evapotranspiration from temperature, Applied Engineering in Agriculture, 1, 96-99.

Hargreaves L.G., Hargreaves G.H. and Riley J.R. (1985), Irrigation water requirements for Senegal River Basin, Journal of Irrigation and Drainage Engineering, 111, 265-275.

Haykin, S. (1994), Neural networks: A comprehensive foundation, Macmillan, New York.

Hoaglin D.C., Mosteller F. and Tukey J.W. (1985), Exploring data tables, trends and shapes, John Wiley and Sons, New York.

Karunanithi N., Grenney W.J., Whitley D. and Bovee K. (1994), Neural networks for river flow forecasting, Journal of Computing in Civil Engineering, 8, 201-218.

Keskin M.E. and Terzi O. (2006), Artificial neural network models of daily pan evaporation, Journal of Hydrologic Engineering, 11, 65-70.

Khoob A.R. (2008), Arificial neural network estimation of reference evapotranspiration from pan evaporation in a semi-arid environment, Irrigation Science, 27, 35-39.

Kim S. and Kim H.S. (2008), Neural networks and genetic algorithm approach for nonlinear evaporation and evapotranspiration modeling, Agricultural Water Management, 351, 299-317.

Kisi O. (2006), Generalized regression neural networks for evapotranspiration modeling, Hydrological Sciences Journal, 51, 1092-1105. 
Kisi, O. (2007), Evapotranspiration modeling from climatic data using a neural computing technique, Hydrological Processes, 21, 1925-1934.

Kisi O. (2008), The potential of different ANN techniques in evapotranspiration modeling, Hydrological Processes, 22, 2449-2460.

Kumar M., Basndyopadhyay A., Raghuwanshi N.S. and Singh R. (2008), Comparative study of conventional and artificial neural network-based $\mathrm{ET}_{0}$ estimation models, Irrigation Science, 26, 531545.

Kumar M., Raghuwanshi N.S. and Singh R. (2009), Development and validation of GANN model for evapotranspiration estimation, Journal of Hydrologic Engineering, 14, 131-140.

Kumar M., Raghuwanshi N.S., Singh R., Wallender W.W. and Pruitt W.O. (2002), Estimating evapotranspiration using artificial neural network, Journal of Irrigation and Drainage Engineering, 128, 224-233.

Landeras G., Ortiz-Barredo A. and Lopez J.J. (2009), Forecasting weekly evapotranspiration with ARIMA and artificial neural network models, Journal of Irrigation and Drainage Engineering, 135, 323-334.

Lekkas D.F., Onof C., Lee M.J. and Baltas E.A. (2004), Application of artificial neural networks for flood forecasting, Global NEST Journal, 6, 205-211.

Li S., Wunsch D.C., O'Hair E. and Giesselmann M.G. (2002), Extended Kalman filter training of neural networks on a SIMD Parallel Machine, Journal of Parallel and Distributed Computing, 62, 544-562.

Loukas A., Vasiliades L. and Dalezios N. (2002), A hydrologic modeling procedure using a watershed model and artificial neural networks, Proc. of Inter. Conf., Water Resources Management in the ERA of Transition, European Water Resources Association, Athens, 219-228.

Maier H.R. and Dandy G.C. (2000), Neural Networks for the prediction and forecasting of water resources variables: a review of modeling issues and applications, Environmental Modelling and Software, 15, 101-124.

Norusis M.J. (2000), SPSS for Windows, SPSS Inc. Chicago.

Prechelt L. (1997), Investigation of the CasCor family of learning algorithms, Neural Network, 10, 885896.

Reynolds M.R.J. (1984), Estimating the error in model predictions, Forest Science, 30, 454-469.

Rivals I. and Personnaz L. (1998), A recursive algorithm based on the extended Kalman filter for the training of feed forward neural models, Neurocomputing, 20, 279-294.

Samani Z. (2000), Estimating solar radiation and evapotranspiration using minimum climatological data, Journal of Irrigation and Drainage Engineering, 126, 265-267.

Sudheer K.P., Gosain A.K. and Ramasastri K.S. (2003), Estimating actual evapotranspiration from limited climatic data using neural computing technique, Journal of Irrigation and Drainage Engineering, 129, 214-218.

Trajkovic S. (2005), Temperature-based approaches for estimating reference evapotranspiration, Journal of Irrigation and Drainage Engineering, 131, 316-323.

Trajkovic S. (2007), Hargreaves versus Penman-Monteith under humid conditions, Journal of Irrigation and Drainage Engineering, 133, 38-42.

Trajkovic S., Todorovic B. and Stankovic M. (2003), Forecasting of reference evapotranspiration by artificial neural networks, Journal of Irrigation and Drainage Engineering, 129, 454-457.

Vanderlinden K., Giráldez J.V. and Meirvenne M.V. (2004), Assessing reference evapotranspiration by the Hargreaves method in Southern Spain, Journal of Irrigation and Drainage Engineering, 130, 184191.

Wang Y.M., Kerh T. and Traore S. (2009), Neural networks approaches for modeling river suspended sediment concentration due to tropical storms. Global NEST Journal, 11, 457-466.

Willmott C.J. (1981), On the validation of model, Physical Geography, 2, 184-194. 